\title{
PENGGUNAAN CONTENT MANAGEMENT SYSTEM WORDPRESS PADA TOKO REDSOUL UNTUK PENERAPAN APLIKASI E-COMMERCE
}

\author{
Mohamad Aseprudin ${ }^{1)}$, Grace Gata ${ }^{2)}$ \\ ${ }^{1}$ Sistem Informasi, Fakultas Teknologi Informasi, Universitas Budi Luhur \\ 1,2 Jl. Raya Ciledug, Petukangan Utara, Kebayoran Lama, Jakarta Selatan 12260 \\ E-mail : mohamadaseprudin@gmail.com ${ }^{1)}$, grace.gata@budiluhur.ac.id ${ }^{2}$ )
}

\begin{abstract}
Abstrak
Perkembangan internet yang sangat cepat membawa dampak besar bagi segala aspek, tidak terkecuali dalam bidang bisnis dan pemasaran. Kemudahan yang diberikan internet membuat banyak pelaku bisnis berpindah dari bisnis konvesional menjadi bisnis elektronik. E-Commerce merupakan konsep perkembangan dalam sistem perdagangan yang bisa digambarkan sebagai proses jual beli produk dan jasa melalui internet. Kelebihan bisnis menggunakan internet antara lain adalah mudah dan cepat. Toko RedSoul merupakan toko pakaian anak yang berlokasi di Tanah Abang dan hanya menggunakan sistem transaksi konvesional. Sebagaimana menjalankan bisnis, pemilik toko ingin mengembangkan bisnisnya menggunakan website penjualan online dengan tujuan menggali potensi pelanggan yang lebih luas dan bisa selalu terhubung dengan pelanggan. Tujuan penelitian ini adalah dengan dibuatnya toko online yang dapat memberi solusi bagi masalah yang terjadi dan meningkatkan penjualan produk. Metode yang digunakan untuk penelitian ini adalah Research Applied (penelitian terapan), pembuatan web menggunakan Content Management System(CMS) Wordpress dan pengoptimalan web menggunakan Search Engine Optimization (SEO). Hasil dari penelitian ini dapat menguntungkan semua pihak, baik pelanggan maupun pemilik toko.
\end{abstract}

Kata kunci: Business Model Canvas, CMS, E-commerce, SEO, Wordpress

\section{PENDAHULUAN}

Sebagaimana menjalankan bisnis, Toko RedSoul ingin mengembangkan bisnisnya menggunakan web E-commerce yang berguna menggali potensi pelanggan yang lebih luas dan bisa selalu terhubung dengan pelanggan. Karena penjualan melalui penggunaan media sosial seperti Instagram tidak terlalu berpengaruh signifikan terhadap penjualan, maka Toko RedSoul menginginkan adanya web E-Commerce yang selain dapat memberikan pelanggan akses lebih mudah untuk mencari informasi produk dan dapat juga meningkatkan penjualan Toko RedSoul.

Dengan begitu, adanya web E-Commerce dapat menghemat waktu dari pelanggan dan dapat menjadi pilihan lain dari penjualan Toko RedSoul. Dalam pembuatan web E-Commerce pada Toko RedSoul, untuk membuat identitas yang mudah dikenali, maka nama atau alamat dari web yang digunakan adalah redsoulkids.com.

Dari latar belakang yang telah dijabarkan maka dapat disimpulkan, yaitu: Penggunaan Media Sosial sebagai sarana promosi tidak digunakan secara maksimal dan tidak adanya promosi kepada pelanggan menyebabkan Toko Redsoul kesulitan mendapakan pelanggan.

Tujuan dari penelitian yang dilakukan di Toko RedSoul adalah sebagai perancangan web $E$ Commerce dapat membantu Toko RedSoul dalam memberikan informasi kepada pelanggan, terdapatnya fasilitas baru untuk pelanggan memesan produk secara online ke Toko RedSoul, membuka peluang meraih pelanggan baru degan web $E$ Commerce karena dapat diakses dimana saja dan kapan saja dan tersedianya pengolahan data pembuatan laporan untuk startegi pemasaran berikutnya.

Metode penelitian yang digunakan dalam menyelesaikan permasalahan dalam penelitian ini adalah Research Applied (penelitian terapan) dengan tujuan agar Toko RedSoul dan pelanggannnya dapat merasakan dampak dan manfaat dari penelitian secara langsung.

Setelah tahap analisis sistem selesai dilakukan, maka analis sistem telah mendapatkan gambaran dengan jelas apa yang harus dikerjakan. Pada dasarnya perancangan sistem bergerak dari input menuju ke output sistem, yang terdiri dari reports dan file untuk memenuhi kebutuhan organisasi. Perancangan sistem merupakan sebuah penentuan proses data yang diperlukan oleh sistem baru, dan tahap-tahap dalam merancang sistem[1].

Business Model Canvas (BMC) salah satu alat strategi yang digunakan untuk mendeskripsikan sebuah model bisnis dan menggambarkan dasar pemikiran tentang bagaimana organisasi menciptakan, memberikan, dan menangkap nilai. Terdapat pendekatan bisnis model kanvas yaitu 
"Nine Building Blocks" yang memudahkan bagi para pebisnis untuk membangun dan mengembangkan bisnis mereka. Nine Building Blocks terdiri dari: Value Proportitions, Customer Segments, Customer Relationship, Channels, Key Resources, Key Activity, Key Partnership, Cost Structure, dan Revenue Stream. BMC dapat mengubah konsep bisnis yang rumit menjadi sederhana yang ditampilkan pada satu lembar kanvas berisi rencana bisnis dengan sembilan elemen kunci yang terintegrasi dengan baik didalamnya mencangkup analisis strategi secara internal maupun ekternal perusahaan[2].

CMS (Content Management System) adalah suatu sistem yang digunakan untuk mengelola dan memfasilitasi proses pembuatan, pembaharuan, dan publikasi konten secara bersama (collaborative content management). Konten mengacu pada informasi dalam bentuk teks, grafik, gambar maupun dalam format-format lain yang perlu dikelola dengan tujuan memudahkan proses pembuatan, pembaharuan, distribusi, pencarian, analisis, dan meningkatkan fleksibilitas untuk ditransformasikan ke dalam bentuk lain. Terminologi CMS sendiri cukup luas, di antaranya mencakup software aplikasi, database, arsip, workflow, dan alat bantu lainnya yang dapat dikelola sebagai bagian dari mekanisme jaringan informasi suatu perusahaan maupun global[3].

Search Engine Optimization (SEO) merupakan sebuah cara, teknik dan juga bisa dikatakan sebuah seni yang digunakan dalam hal mendesain, mengembangkan, memodifikasi dan membangun sebuah halaman website yang memiliki tingkat visibilitas serta peringkat yang tinggi dalam hasil pencarian. Terdapat 2 macam teknik SEO yaitu SEO on page dan SEO off page. SEO on page adalah teknik-teknik yang digunakan pada halaman website dengan cara memodifikasi bagian-bagian website seperti content, link, tag, kata kunci sedangan SEO off page adalah teknik yang dilakukan diluar website[4].

Perdagangan elektronik atau e-dagang (bahasa Inggris: Electronic commerce atau E-Commerce) adalah penyebaran, pembelian, penjualan, pemasaran produk dan jasa melalui sistem elektronik seperti internet atau televisi, www, atau jaringan komputer lainnya. E-Commerce dapat melibatkan transfer dana elektronik, pertukaran data elektronik, sistem manajemen inventori otomatis, dan sistem pengumpulan data otomatis[5].

Penelitian sebelumnya di [5], bermaksud memberi solusi pemecahan masalah pada Toko Kun dalam masalah penjualan dengan merancang sebuah sistem informasi berbasis ecommerce dengan metode waterfall yang menjelaskan tentang Analisis, Desain, Kode Program dan Pengujian. Hasil penelitian ini menunjukan pemanfaatan sistem informasi penjualan menggunakan web e-commerce dapat memudahkan pelanggan dalam melakukan transaksi dan pencarian informasi produk secara online.

\section{METODE PENELITIAN}

\subsection{Kerangka Penelitian}

Berikut merupakan langkah-langkah yang dilakukan dalam penelitian pada Toko RedSoul.

Pada Gambar.1 terdapat kerangka penelitian dengan penjelasan sebagai berikut:

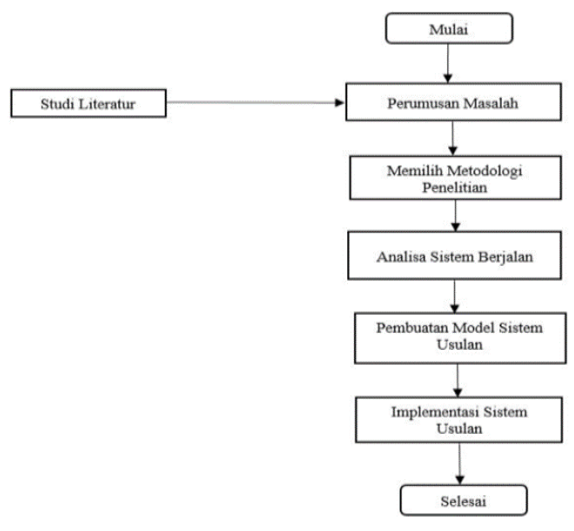

Gambar 1. Kerangka Penelitian

a. Perumusan Masalah

Perumusan masalah merupakan hasil dan kesimpulan dari kegiatan peneliti melakukan observasi dan wawancara langsung kepada Pemilik Toko RedSoul.

b. Studi Literatur

Studi literatur ini dilakukan dengan cara mencari dan membaca buku, jurnal, presensi ataupun karya ilmiah lainnya yang berhubungan dengan permasalahan yang sedang dihadapi dan penelitian yang sedang dikerjakan.

c. Menentukan Metode Penelitian

Metodologi penelitian yang digunakan dalam menyelesaikan permasalahan dalam penelitian ini adalah Research Applied (penelitian terapan) supaya Toko RedSoul dan pelanggannnya dapat merasakan dampak dan manfaat dari penelitian secara langsung. d. Analisa Sistem Berjalanan

Pada tahap ini Activity Diagram digunakan untuk melakukan analisa dan penguraian proses bisnis berjalan dalam ruang lingkup penelitian.

e. Membuat Sistem Model Usulan

Pada pembuatan tahap ini peneliti menggunakan tool Use Case Diagram. Dengan melakukan sebuah identifikasi kebutuhan sistem usulan, memodelkan sistem usulan. Spesifikasi basis 
data menggunakan model data Interaction Flow Modeling Language dan Class Diagram.

f. Implementasi Sistem Usulan

Pengimplementasian model sistem usulan pada penelitian ini menggunakan Content Management System (CMS) Wordpress.

\subsection{Teknik Analisis Data}

a. Activiy Diagram

Digunakan untuk menggambarkan aliran aktivitas pada sebuah proses bisnis mulai dari aliran awal, keputusan-keputusan yang mungkin terjadi hingga aktivitas berkahir.

b. Use Case Diagram

Use Case Diagram digunakan untuk merepresentasikan sebuah interaksi antar aktor (dalam hal ini user) dengan sistem.

c. Deskripsi Use Case

Deskripsi Use Case digunakan untuk memberikan gambaran umum tentang Use case diagram yang telah dibuat.

\subsection{Tahap Pengumpulan Data}

Data yang diperoleh pada penelitian ini dikumpulkan dengan menggunakan beberapa metode, diantaranya adalah:

a. Wawancara

Wawancara dilakukan langsung kepada Teguh Setiadi pemilik Toko Redsoul guna mendapati masalah apa yang dialami atau timbul ketika melakukan penjualan. Dalam wawancara ini peneliti mengajukan beberapa pertanya lisan yang berupaya untuk melengkapi data yang akan diperoleh.

b. Observasi

Tahap ini dilakukan dengan cara datang langsung ke Toko Redsoul dan mengamati proses bisnis yang sedang berjalan guna mempelajari dan meniliti permasalahan yang akan dibahas.

c. Literatur

Tahap ini dilakukan guna mendapatkan teori yang dibutuhkan dalam penyelesaian permasalahan pada penelitian ini. Metode yang peneliti lakukan dalam studi literatur adalah dengan membaca berbagai buku, jurnal, presensi ataupun karya ilmiah lainnya yang telah di publikasikan secara umum.

d. Teknik Dokumentasi

Teknik dokumentasi ini dilakukan dengan cara mengumpulkan dan menganalisa dokumen-dokumen dan laporan transaksi pada proses bisnis berjalan yang telah dibuat oleh Toko RedSoul.

\subsection{Business Model Canvas (BMC)}

Berikut merupakan Business Model Canvas yang dilakukan dalam penelitian pada Toko RedSoul.

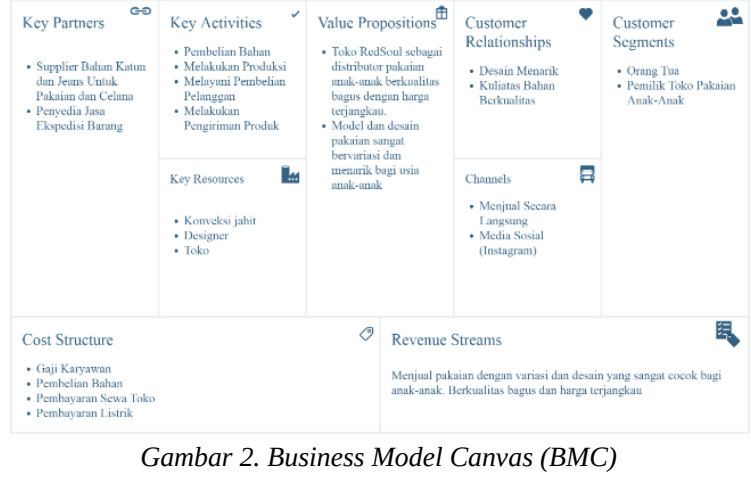

Merujuk pada Gambar.2 pengolahan data dilakukan menggunakan metode Business Model Canvas dan penjelasanya adalah sebagai berikut:

a. Key Partnership

Kemampuan Toko RedSoul dalam menciptakan hubungan baik dengan supplier adalah salah satu faktor kekuatan dalam elemen ini. Supplier Toko RedSoul adalah supplier bahan berkualitas untuk membuat pakaian dan jasa ekspedisi pengiriman.

b. Key Activities

Beberapa aktivitas yang dilakukan terdiri dari: Pembelian bahan untuk pembuatan pakaian, melakukan produksi pembuatan pakaian, melayani pembelian oleh pelanggan dan melakukan pengiriman produk.

c. Key Resources

Beberapa Resource toko RedSoul antara lain: Konveksi Jahit, Designer dan Penyewaan Toko.

d. Customer Relationship

Dalam Customer Relationship toko RedSoul sebagai distributor pakaian anak-anak terus membuat produk yang menarik untuk anak-anak dengan bahan berkualitas bagus.

e. Value Propositions

Pada Toko RedSoul sesuatu yang dianggap menarik perhatian pelanggan adalah pakaian anakanak yang dijual memiliki kualitas yang bagus dengan harga terjangkau dan model dari baju dan celana bervariasi dibergagai usia anak-anak.

\section{f. Channles}

Kelemahan pada elemen ini yaitu proses distribusi informasi dan penjualan hanya dilakukan secara langsung ketika pelanggan datang ke toko. Pengguan Sosial Media (Instagram) yang tidak dimaksimalkan dengan baik membuat informasi dan penjualan toko RedSoul lebih banyak didapat ketika pelanggan datang ke toko.

g. Customer Segments

Kekuatan pada elemen ini adalah Toko RedSoul sudah memiliki Customer Segment yang jelas, yaitu toko-toko pakaian anak-anak yang membeli produk secara lusinan. 
Kelemahan pada elemen ini yaitu tidak terlalu banyak individu yang mengetahui Toko RedSoul.

h. Cost Structure

Di toko RedSoul biaya-biaya yang dikeluarkan antara lain:
1) Gaji karyawan
2) Pembelian bahan
3) Pembayaran sewa toko
4) Pembayaran listik

i. Revenue Streams

Toko RedSoul hanya memperoleh pendapatan dari penjualan pakaian anak-anak.

\section{HASIL DAN PEMBAHASAN}

\subsection{Activity Diagram}

Tahap analisa sistem dalam pembuatan web $E$ Commerce ini dibuat dalam Activity Diagram.

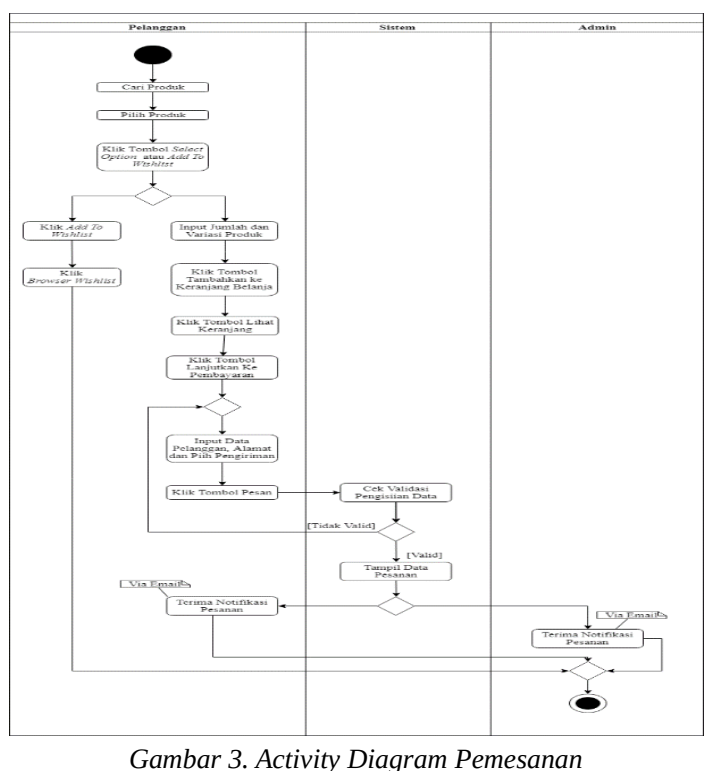

Pada Gambar.3 terdapat Activity Diagram Pemesanan dengan penjelasan pelanggan yang ingin membeli produk di e-commerce dengan cara mencari dan memilih produk yang akan dibeli pada halaman katalog toko, pada produk yang dipilih klik bagian pilih opsi untuk menuju halaman detail pemesanan, lalu pelanggan dapat mengisi model dan jumlah pembelian produk. Selanjutnya klik tombol tambah ke keranjang belanja, pelanggan dapat memilih produk lain setelah menambahkan produk ke keranjang belanja. Jika sudah ingin melakukan pembayaran, pelanggan dapat melakukan checkout yang terdapat di menu keranjang belanja. Pada halaman detail pembayaran pelanggan menginput nama, alamat lengkap, nomor telepon, alamat email dan memilih kurir pengiriman. Jika sudah klik tombol process order, lalu Admin akan mendapatkan pemberitahuan transaksi baru melalui e-mail dan pelanggan mendapatkan email pemesanan serta pembayaran.

\subsection{Struktur Menu}

Terdapat Struktur menu pelanggan yang berguna untuk mengarahkan pelanggan pada saat membuka halaman web.

Pada Gambar 4. terdapat 6 menu yang bisa diakses oleh pelanggan, yaitu Home, Produk, Konfirmasi pembayaran, Panduan ukuran, My Account dan Cart .

\subsection{Tampilan Layar}

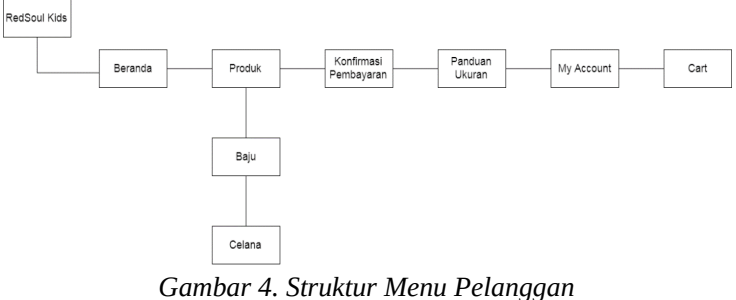

a. Tampilan Layar Home

Pada Gambar 5. merupakan tampilan layar Home ketika pelanggan mengakses web toko Redsoul

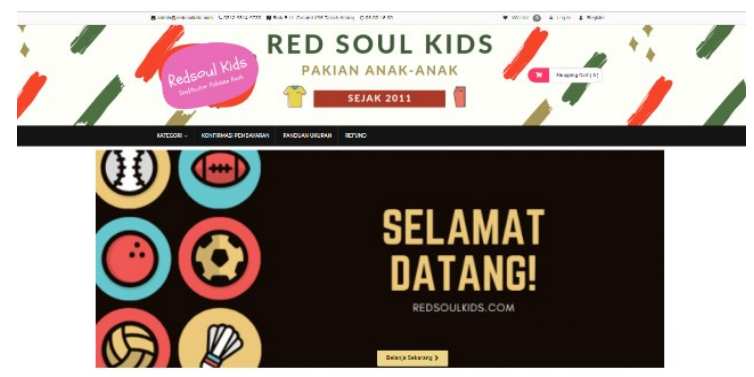

Gambar 5. Tampilan Layar Home

b. Tampilan Layar Pemesanan

Pada Gambar 6. merupakan tampilan layar pemesanan ketika pelanggan memilih produk yang ingin dipesan. Dalam Layar Pemesanan terdapat opsi ukuran dan detail ukuran, deskripsi dan infromasi tambahan yang terkait pada produk yang dipilih tersebut.
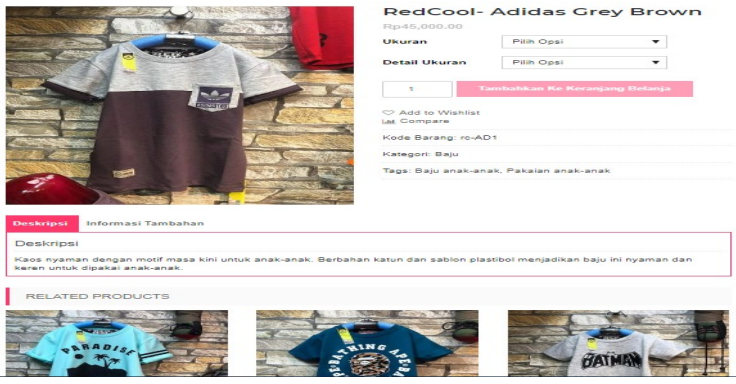

Gambar 6. Tampilan Layar Pemesanan 
c. Tampilan Layar Pembayaran

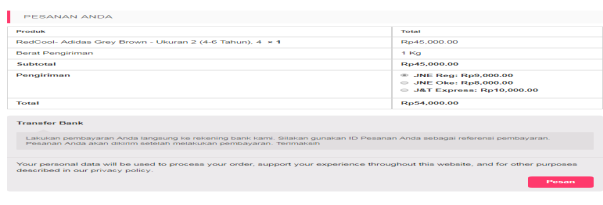

Gambar 7. Tampilan Layar Pembayaran

Pada Gambar 7. terdapat detail pemesanan yang berisi produk yang dipesan, berat produk yang dipesan, tarif ongkos kirim sesuai alamat yang dipilih dan total yang harus dibayar.

d. Tampilan Layar Konfrimasi Pembayaran

Pada Gambar 8. tampilan konfirmasi pembayaran terdapat form yang harus diisi pelanggan setelah melakukan pembayaran.

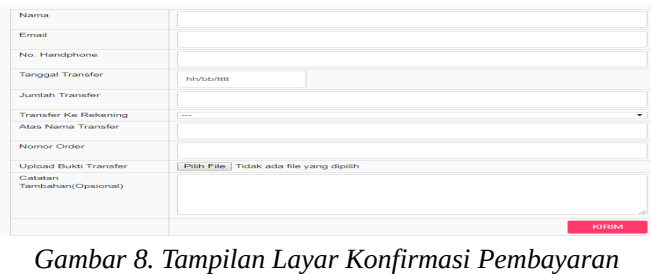

e. Tampilan Layar Kelola Transaksi

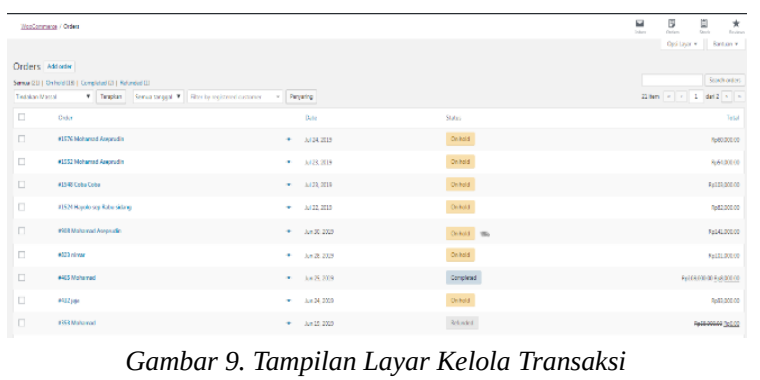

Gambar 9. merupakan tampilan layar yang digunakan oleh admin untuk mengelola transaksi, terdapat 7 pilihan dalam menu pengolahan, yaitu: pending payment, on hold, processing, completed, cancelled, refunded dan failed.

\subsection{4 Hasil Keluaran}

a. Invoice

Merupakan nota yang didapat pelanggan melalui email ketika melakukan pembayaran.

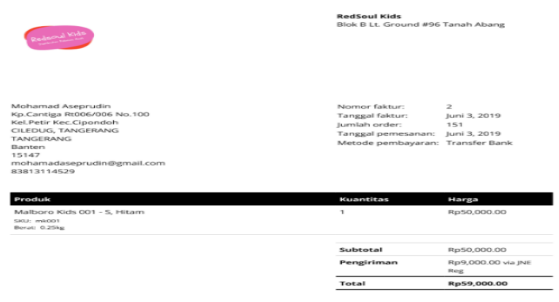

Gambar 10. Invoice
Dari Gambar 10. invoice terdapat nama dan alamat lengkap, nomor nota, tanggal pemesanan, jumlah order, metode pembayaran, produk yang dipesan dan total harga yang harus dibayar.

b. Laporan Pemesanan

Laporan pemesanan merupakan laporan yang diunduh admin dan diberikan kepada kepala toko untuk melihat seberapa besar perkembangan web toko Redsoul.

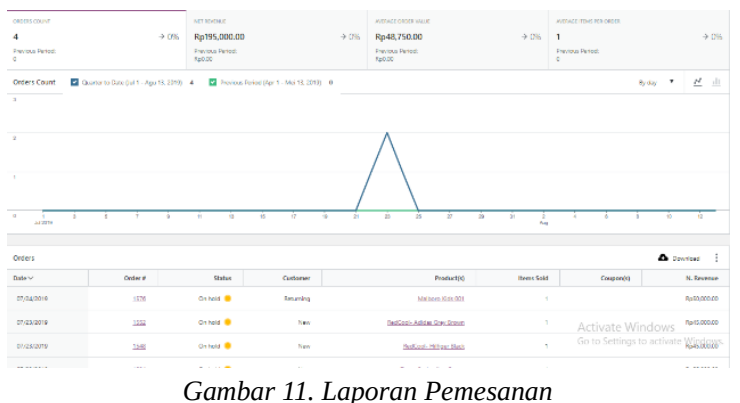

Merujuk pada Gambar 11. pada laporan pemesanan terdapat tabel-tabel date, order, status, customer, product, item sold, coupon dan net revenue.

c. Laporan Produk

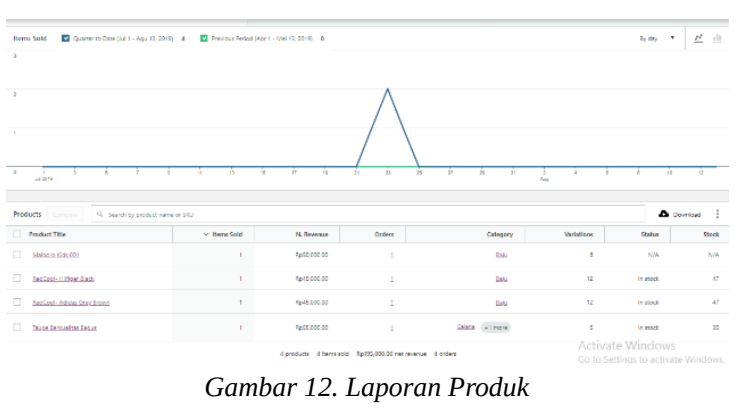

Laporan penjualan merupakan laporan yang diunduh admin dan diberikan kepada kepala toko untuk melihat produk apa yang paling banyak terjual dan produk yang paling sedikit terjual.

Merujuk pada Gambar 12. laporan produk terdapat tabel-tabel product/variation, SKU, status dan stock.

\section{KESIMPULAN}

Berdasarkan dari hasil analisa masalah dan pembahasan, maka dapat mengambil kesimpulan, yaitu dengan adanya penerapan web E-Commerce, toko RedSoul dapat dapat menghemat waktu dari pelanggan dan dapat menjadi pilihan lain dari penjualan Toko RedSoul Selain itu pihak toko dapat memberikan informasi kepada pelanggan secara langsung, membuka peluang meraih pelanggan baru degan web E-Commerce karena dapat diakses dimana saja dan kapan saja dan tersedianya 
pengolahan data pembuatan laporan untuk startegi pemsaran berikutnya.

Agar penerapan web E-Commerce ini dapat berjalan dengan semestinya dan dapat berkembang, maka saran yang dapat diberikan adalah melakukan update produk dan informasi secara rutin agar pelanggan mengetahui informasi baru dan melakukan optimasi lanjutan terhadap web $E$ Commerce yang telah dibuat sehingga semakin banyak pelanggan baru yang berbelanja.

\section{DAFTAR PUSTAKA}

[1] D. Abdullah, Herawati, dan C. I. Herliana, "Perancangan Sistem Informasi Pendataan Siswa SMP Islam Swasta Darul Yatama Berbasis Web," IJNS - Indones. J. Netw. Secur., vol. 4, no. 1, hal. 39-44, 2015.

[2] F. Priyono, "Analisa Penerapan Business Model Canvas Pada Toko Moi Collection,” Agora, vol. 3, no. 2, hal. 358-363, 2015.

[3] H. Al Fatta dan R. Marco, "Analisi Pengembangan Dan Perancangan Sistem Informasi Akademik Smart Berbasis Cloud Computing Pada Sekolah Menengah Umum Pertama Negeri(SMUN) Di Daerah Istemewa Yogjakarta,” Naskah Publ., vol. 3, no. 10, hal. 64-91, 2015.

[4] R. B. Halilintar dan D. Ariyus, "Implementasi Seo ( Search Engine Optimization ) Pada Website Agc ( Auto Generated Content ) Untuk Meningkatkan Serp ( Search Engine Result Page ) Studi Kasus : Website Gallery,” hal. 13-18, 2018.

[5] S. Handayani, "Perancangan Sistem Informasi Penjualan Berbasis E-Commerce Studi Kasus Toko Kun Jakarta,” Ilk. J. Ilm., vol. 10, no. 2, hal. 182, 2018. 